\title{
Violence Towards Emergency Residents in Malaysia: The Unforeseen Perpetrators Among Us
}

\author{
(1) Rashidi Bin Ahmad¹, (1) Amelia Binti Amir¹, (1) Nur Fithriyaani Rashidi2 \\ 1Department of Emergency Medicine, University Malaya Medical Centre, Kuala Lumpur, Malaysia \\ ${ }^{2}$ Faculty of Social Sciences, College University Islam of Malacca, Melaka, Malaysia
}

\begin{abstract}
Aim: Workplace violence in the emergency department (ED) is a common occurrence worldwide, affecting staff across all roles, compromising the safety, health, self-esteem, and job satisfaction of healthcare workers. Combating workplace violence in healthcare settings is a massive challenge as the problem's true scope is unknown due to insufficient documentation or underreporting. Thus, this study aims to explore and examine the magnitude and attitude of ED residents (ERs) towards workplace violence.

Materials and Methods: This study is a single centre, questionnaire-based, anonymous, and self-administered cross-sectional survey involving 63 ERs. A chi-square test examined the relationship between variables. Composite measures condensed the vast number of variables data into a single indicator.

Results: Workplace violence in ED was reported by $93.6 \%$ of respondents. Verbal assault (88.9\%) was the predominant form of violence. Unforeseen perpetrators include physicians (17.5\%), non-ED staff of the hospital (17.5\%) and other ED staff (14.3\%). The common site of violence occurrence was a non-critical area (81\%). There was no significant relationship between attitude and gender $(p=0.93)$ or race $(p=0.70)$ or designation $(\mathrm{p}=0.45)$. Composite measure of attitude scores revealed that $50.8 \%$ of respondents had a positive attitude towards workplace violence in ED.

Conclusion: Violence among ERs is an undeniable existence. Co-worker as the perpetrator is not acceptable at all. A continuous effort from ERs, ED staff and ED managers is required to mitigate the growing phenomenon of workplace violence in ED.

Keywords: ED residents, prevalence, attitude, workplace violence
\end{abstract}

\section{Introduction}

Emergency departments (ED) has high stress environment that associated with violent acts (1-3). Violence in ED creates unhealthy environment such as reduce self-esteem, impaired staff perception and attention, dissatisfaction, and burnout to all level of ED workers including emergency residents (ERs) $(4,5)$. As a result, it may affect the overall quality of emergency service (6).

Combating workplace violence in healthcare settings is a massive challenge as the true scope of the problem is not known due to scarcity of documentation and underreporting $(7,8)$. The lack of a universally accepted definition of workplace violence and measurement tools have also contributed to the difficulty in measuring the true percentage, magnitude, and scope of violence against healthcare providers $(9,10)$.

Despite of workplace violence being a common occurrence among ERs, the prevalence of workplace violence among ERs and their attitude towards it have not been well explored that leaving significant knowledge gap in this psychosocial issue (11-13).

In this study we investigated the magnitude of workplace violence in ED and ERs attitude towards workplace violence. The findings from this study may change our perception towards the management of violence in ED and it may assist in apprising and 
updating the national healthcare policy on the management of violence at workplace.

\section{Materials and Methods}

\section{Study Design}

This 6-months period of a questionnaire-based, anonymous, and self-administered cross-sectional survey was conducted at Hospital Sungai Buloh (HSB) from June 2018 to November 2018. HSB is a tertiary hospital governed by Malaysian Ministry of Health. It is located at suburban area (Petaling District, Selangor) and its distance from Kuala Lumpur, Capital City of Malaysia is $20 \mathrm{~km}$ apart.

All ERs (house officers, medical officers, and specialists) were invited to participate in the study. Non-ERs and ERs who participated in the validation of KPA questionnaires were excluded.

\section{Study Instrument}

All the relevant data was collected and documented into the paper-based self-administered questionnaire that was developed by the researcher after an extensive review of literature. Face validity was established by experts in the fields of emergency medicine and occupational violence, all of whom were independent of the study.

The questionnaire developed for this study is in English language as it is the universal language and it enables international comparisons. The questionnaire was not translated into other languages to prevent unintended deviations, to preserve the intended meaning and the measurement properties of the source questionnaire. The first section of the questionnaire seeking demographic characteristics of study population. The second section inquiring the prevalence of workplace violence and investigating respondents' knowledge, attitude, and practice towards workplace violence.

We instructed expert panels to rate level of representativeness, importance, clarity, and relevance of each item on the questionnaire. The design questionnaire was subsequently pilot tested on a sample of 10 participants. The reliability of the questionnaire was established by Cronbach's alpha and the values for each construct, namely knowledge, attitude and practice are $0.75,0.75$ and 0.79 respectively, suggesting accepted level of reliability.

\section{Enrolment Procedure}

Participation in this study was voluntary and all data were treated as strictly confidential. The participants were provided with verbal and written information about the study. The questionnaires were administered at various times and shifts to ensure confidentiality. The completed questionnaires were placed into a sealed and secured box, they were subsequently collected by the researcher.

\section{Statistical Analysis}

Statistical analysis was performed using SPSS (Version 16.0). Variables were reported as mean [standard deviation (SD)] and percentage (\%) for numerical and categorical data respectively.

A Chi-square test was performed to explore and analysis the relationship between independent variables and dependent variables (knowledge, attitude and practice). Point estimation from the general population mean with a lower and upper bound of $95 \%$ confidence interval was calculated using SPSS. A value of $p<0.05$ was statistically significant.

Composite measure was applied to condense the vast number of variables data into a single indicator, hence, it summarises a range of quality dimensions.

\section{Results}

Seventy set of questionnaires were distributed among ERs and 63 (90.0\%) of ERs completed and returned the questionnaires.

\section{Demographics of Participants}

The sociodemographic of respondents were presented in Table 1. The mean age (SD) of participants was 31 (3.7) years. Female was the predominant gender (65.1\%). Majority of the respondents were medical officers (69.8\%).

\begin{tabular}{|c|c|c|}
\hline & n (\%) & Mean (SD) \\
\hline Age & - & $31(3.7)$ \\
\hline Years of practice & - & $6(3.7)$ \\
\hline \multicolumn{3}{|l|}{ Gender } \\
\hline Male & $22(34.9 \%)$ & - \\
\hline Female & $41(65.1 \%)$ & - \\
\hline \multicolumn{3}{|l|}{ Race } \\
\hline Malay & $38(60.3 \%)$ & - \\
\hline Chinese & $9(14.3 \%)$ & - \\
\hline Indian & $12(19.0 \%)$ & - \\
\hline Others & $4(6.3 \%)$ & - \\
\hline \multicolumn{3}{|l|}{ Designation } \\
\hline Specialist & $12(19.0 \%)$ & - \\
\hline Medical officer & $44(69.8 \%)$ & - \\
\hline House officer & $7(11.1 \%)$ & - \\
\hline
\end{tabular}




\section{Magnitude of Workplace Violence in ED}

We presented the prevalence of workplace violence among ERs in Table 2. Majority of respondents (93.6\%) reported that they have experienced workplace violence in ED.

The most shared form of violence experienced by respondents was verbal assault (88.9\%). The distribution rate of emotional violence, physical violence and sexual assault were $69.8 \%, 30.2 \%$ and $1.6 \%$ respectively. Relatives of patient was the most common perpetrators of violence in ED (88.9\%) followed by patient's himself (79.4\%). Other perpetrators were clinical specialists (17.5\%), non-ED staff of hospital (17.5\%) and ED staff (14.3\%). Violence took place recurrently at non-critical zone (81.0\%).

\section{ERs Attitude Towards Workplace Violent}

Personal safety at work are dreadful among most respondents (73.0\%). This study revealed $41.2 \%$ of respondents felt threatened working in the non-critical area and waiting area. The distribution of violence frequency based on working area of triage zone, semicritical zone, critical zone, and observation ward were 39.6\%, $19.1 \%, 11.1 \%$ and $9.5 \%$ respectively. About $70.0 \%$ of respondents perceived that 'workplace violence is simply part of their job in the ED. However, more than three quarter of the respondents (79.3\%) claimed of having upsetting feelings after experiencing the uneventful event.

\begin{tabular}{|l|l|}
\hline \multicolumn{2}{|l|}{ Table 2. Prevalence of workplace violence } \\
\hline \multicolumn{2}{|l|}{$\mathbf{n}(\%)$} \\
\hline Experience of workplace violence in ED \\
\hline Yes & $59(93.6 \%)$ \\
\hline No & $4(6.3 \%)$ \\
\hline Form of violence & $56(88.9 \%)$ \\
\hline Verbal & $44(69.8 \%)$ \\
\hline Emotional & $19(30.2 \%)$ \\
\hline Physical & $1(1.6 \%)$ \\
\hline Sexual & \multicolumn{2}{|l|}{} \\
\hline Perpetrators & $56(88.9 \%)$ \\
\hline Relatives of patients & $50(79.4 \%)$ \\
\hline Patients & $11(17.5 \%)$ \\
\hline Specialists & $11(17.5 \%)$ \\
\hline Non-ED staff of hospital & $9(14.3 \%)$ \\
\hline General public & $9(14.3 \%)$ \\
\hline ED staff & $51(81.0 \%)$ \\
\hline Area & $5(7.9 \%)$ \\
\hline Non-critical zone & $4(6.3 \%)$ \\
\hline Semi-critical zone & \\
\hline Triage & \multicolumn{2}{|l|}{} \\
\hline ED: Emergency department, n: Number & \\
\hline
\end{tabular}

Composite measure of attitude scores revealed $50.8 \%$ of respondents had positive attitude towards workplace violence in ED.

Chi-square analysis did not demonstrate a significant relationship between attitude and gender $(p=0.93)$ or race $(p=0.70)$ or designation $(p=0.45)$.

\section{Discussion}

Workplace violence has emerged as an important safety and health issue in today's workplace (6). Workplace hazard is associated with physical and psychological harm risking high costs to employees, workplaces, and society (8). Being violated, beaten, or trampled is a distressing experience that may affect their tasks performance quality and psychosocial stability. Lack of focus on medical condition of patients, incorrect administration of medications and inappropriate communicate were reported among healthcare providers following experiences of workplace violence in $\mathrm{ED}(1,12)$. There were studies demonstrated workrelated violence and threats are associated with psychological distress, depression, anxiety, fatigue, job dissatisfaction, employee absenteeism and job quitting (12-14). In this study, about $80 \%$ of respondents declared that violence at workplace affects their life.

Violence can potentially affect any occupation, any workplace, and any worker, typically occupation involving face-to-face interaction with clients such as healthcare, public administration, hotels, and restaurants $(9,14,15)$. Healthcare staff experience more workplace violence than other industry workers because of high stress environment $(1,16)$. Doctors, nurses, and social workers are all high on the list of occupations with serious stress levels while violence in the health sector constitutes almost a quarter of all violence at work (17). When stress and violence interact at the workplace, their negative effects cumulate in an exponential way, activating a vicious circle which is very difficult to break (18). Focusing on the interrelationship between stress and violence at the workplace, the study identifies negative stress as a cause of violence. The more negative stress is generated, the greater the likelihood of violence, up to the most extreme forms such as burnout, suicide, and homicide. Interestingly, many people under severe negative stress do not become perpetrators of violence (16-18). The combination of stress with several additional factors, such as alcohol or substance abuse may be the violence triggers at the workplace (18).

Health care is not only a high-risk sector as far as stress and violence are concerned, but it is also typically a sector with high levels of female employment. Exposure to the risks of stress and violence is therefore particularly high for women (19). It is even 
higher for certain types of violence, such as sexual harassment, where the victims are predominantly women $(19,20)$. In our study, $65 \%$ of respondents were female gender and they suffered most from verbal abuse instead of sexual abuse (1.6\%).

Among high-risk hospital area of workplace violence were psychiatric ward, the emergency room, or the long-term care facilities (21). From previous studies $(22,23)$, the prevalence of workplace violence in healthcare settings was reported higher than $50 \%$. The prevalence of workplace violence among ERs in our study was extremely high (89.9\%).

In this study, violence took place repeatedly at non-critical zone of ED (81.0\%). Most of the time non-critical area was overwhelmed by patients and subsequently causing overcrowding. Hence, non-critical patients had the longest waiting times, highest levels of stress and dissatisfaction and complaints $(23,24)$.

Attitudes are not directly observable. It represents an intermediate variable between a situation, and the response to the situation, and it could explain the reason for adopting certain practices although many studies have shown no association between attitude and practices (24). ED Staffs may be uncertain what constitutes violence and they perceive violent acts related to illness as unintentional thus may assume formal reporting is unnecessary and they perceive that taking action against patient's unintentional violent behaviour as immoral and will lead to punishment for the patient $(11,25)$.

Majority of respondents accepting violence in $\mathrm{ED}$ as a norm or as it is part of the job because ED has unexpected, unpredictable, and chaotic environment. The ability to control stress and manage the unwanted and unexpected incidents including violence behaviour is a pride for ERs and for them it is a sign of competency $(26,27)$. According to The Emergency Nurses Association national survey (1994), 3\% of ED nurse managers would not report violent incidents because violence was considered part of the job and reporting the incident conflicts with their duty of care (28). Ironically, there was ED managers who take an action against healthcare professionals who report the incident (29). In our opinion, those ERs or ED staffs who view violence as a risk associated with their job were more likely to overlook violent incidents, contributing to underreporting and underestimating workplace violence in ED. We stipulated that this odd thinking or belief together with non-accountability culture may be the main reasons why healthcare staffs themselves are the perpetrator as demonstrated by our study.

There are four categories of workplace violence according the perpetrators by The National Institute for Occupational Safety and Health of U.S (30). Type I incidents are perpetrated by individuals with no legitimate business relationship to the worker or workplace, usually with criminal intent such as robbery. Type II involves a patient or visitor as the perpetrator, Type III involves a co-worker as the perpetrator, and Type IV involves a perpetrator with no business relationship to the workplace but who has a personal relationship to the worker (30).

We noticed that type II was the custom type of workplace violence in our study and unexpectedly type III was the next common. According to ERs respondents, common perpetrators were visitors or family members (88.9\%) and patients themselves (79.4\%). Recent studies estimate that patient and visitor violence against healthcare workers has been increasing in both developed and developing countries $(31,32)$. Personal and situational aspects may contribute to the violence acts (33). The experience of sickness and the processes they must go through as a result may cause fear and anxiety among patients and relatives. In these conditions, patients and visitors are dependent on healthcare staff. Hence, ineffective communication (insufficient, ill-mannered, miscommunication, misunderstandings, shortcomings in the way information is shared between practitioner and patient), lack of trust, unmet expectations, loss of respect for the doctor and the perception of a poor standard of care may contribute to patient and visitor violence include (32-34). Our recommendation to curb type II workplace violent include motivating hospital administrators to improve patient safety, monitoring educational quality of HCPs, violence prevention programs and interpersonal communication skill program for healthcare providers as a strategy for the reduction of workplace violence

In our study, the unforeseen type III perpetrators in ED were specialists/physicians (17.5\%), ED staffs (14.3\%) and non-ED staffs of hospital (17.5\%). Providing care together with multidiscipline teams in overwhelming environment is the nature of emergency care. Power imbalances, interdependence management, greater points of contact between ED staffs with other workers and individual attributes, such as personality, may contribute to interpersonal conflicts among HCPs $(34,35)$. Moreover, working in proximity in a high stress environment, work overload, lack of autonomy, and absence of organizational fairness may contribute to violence between co-workers $(35,11)$. This volatile environment, characterized by insecurity, role conflict, and tension, allows few opportunities for socialization and even less time for conflict resolution may indirectly contribute to the emergence of aggressive behaviours and bullying (11). To curb workplace violence among HCPs, the design and implementation of a system-wide program likely makes more sense. We must take proactive steps to develop educational programs and to cultivate an atmosphere that eradicates the fear of reporting vulgarity. It is a major necessity for workplace violence policy or a code of conduct in place. It is our recommendation that employers give 
serious thought to the establishment and enforcement of codes of conduct that make violence among HCPs a zero-tolerance matter. Type III violent should be stopped!

The principle behind health promotion model is that high knowledge leads to positive attitude and consequently good behaviour, albeit this transition is not always straightforward (36). As hospital staffs or ERs we should be accountable to any violent events in our premise. Therefore, educational approach on the stress and violence should be emphasized to communities and all level of hospital staffs including physicians and administrators. Workplace violence is preventable, and we start by educating ourselves.

\section{Study Limitations}

The questionnaire that was developed for this study was administered in a single centre and sample size was small. Results obtained from this study may did not reflect or represent the whole ERs communities.

This survey can be repeated on a larger scale and at multiple sites to explore more in-depth on the current issue. Studies involving other healthcare personnel besides doctors as well as studies between public and private ED are also required to allow for comparison of results and reasons for differences should be explored.

\section{Conclusion}

Violence among ERs is an undeniable existence and its management is challenging. Co-worker as the perpetrator is not acceptable at all. Regular education and competency training on the identification, notification, and management of workplace violence to hospital staffs indeed may promote the best practice. Hospital administrators including physicians and head department should provide a safe and secure working environment to all level of healthcare personnel. A continuous effort is essential to mitigate the growing phenomenon of workplace violence in ED.

\section{Acknowledgements}

The authors would like to thank and to express their gratitude to the Director of Health Malaysia for permission to publish this paper, the experts, and facilitators from Hospital Sungai Buloh for their contribution to this study. All authors participated sufficiently in the work and agreed to take public responsibility for appropriate portions of the contents.

\section{Ethics}

Ethics Committee Approval: The study was approved by Medical Review and Ethics Committee (MREC), Ministry of Health Malaysia (decision no: NMRR-17-2567-38385(IIR), date: 4th January 2018.
Informed Consent: Participation in this study was voluntary and all data were treated as strictly confidential. The participants were provided with verbal and written information about the study.

Peer-review: External peer-reviewed.

\section{Authorship Contributions}

Surgical and Medical Practices: R.B.A., A.A., Concept: R.B.A., A.A., N.F.R., Design: R.B.A., A.A., Data Collection or Processing: A.A., Analysis or Interpretation: R.B.A., A.A., Literature Search: A.A., N.F.R., Writing: R.B.A., A.A., N.F.R.,

Conflict of Interest: The author(s) declared no potential conflicts of interest with respect to the research, authorship, and/or publication of this article.

Financial Disclosure: The author(s) received no financial support for the research, authorship, and/or publication of this article.

\section{References}

1. Kowalenko T, Walters BL, Khare RK, Compton S; Michigan College of Emergency Physicians Workplace Violence Task Force. Workplace violence: a survey of emergency physicians in the state of Michigan. Ann Emerg Med. 2005;46:142-7.

2. Gacki-Smith J, Juarez AM, Boyett L, Homeyer C, Robinson L, MacLean SL. Violence against nurses working in US emergency departments. J Nurs Adm. 2009;39:340-9.

3. Billy Henson. Preventing interpersonal violence in emergency departments: practical applications of criminology theory. Violence Vict. 2010;25:553-65.

4. Kinkle SL. Violence in the ED: How to stop it before it starts. Am J Nurs. 1993;93: 22-4.

5. Rippon TJ. Aggression and violence in health care professions. J Adv Nurs. 2000;31:452-60.

6. Arnetz JE and Arnetz BB. Violence towards health care staff and possible effects on the quality of patient care. Soc Sci Med. 2001;52:417-27.

7. Kennedy MP. Violence in emergency departments: under-reported, unconstrained, and unconscionable. Med J Aust. 2005;183:362-5.

8. McKinnon B., Cross W. Occupational violence and assault in mental health nursing: A scoping project for a Victorian mental health service. Int J Ment Health Nurs. 2008;17:9-17.

9. Ferns T. Violence in the accident and emergency department - an international perspective. Acad Emerg Nurs. 2005;13:180-5.

10. Kowalenko T, Gates D, Gillespie GL, Succop P, Mentzel TK. Prospective study of violence against ED workers. Am J Emerg Med. 2013;31:197-205.

11. Hesketh KL, Duncan SM, Estabrooks CA, Reimer MA, Giovannetti P, Hyndman $\mathrm{K}$, et al. Workplace violence in Alberta and British Columbia hospitals. Health Policy. 2003;63:311-21.

12. Wieclaw J, Agerbo E, Mortensen PB, Burr H, Tüchsen F, Bonde JP. Workrelated violence and threats and the risk of depression and stress disorders. J Epidemiol Community Health. 2006; 60:771-5.

13. Nielsen KJ, Pedersen AH, Rasmussen K. Work-related stressors and occurrence of adverse events in an ED. Am J Emerg Med. 2013;31:504-8.

14. Woodrow C, Guest DE. Public violence, staff harassment and the wellbeing of nursing staff: an analysis of national survey data. Health Serv Manag Res. 2012;25:24-30.

15. Sabine Hahn, Virpi Hantikainen, Ian Needham, Kok G, Dassen T, Halfens 
RJG. Patient and visitor violence in the general hospital, occurrence, staff interventions and consequences: a cross-sectional survey. J Adv Nurs. 2012;68:2685-99.

16. Phillips JP. Workplace violence against health care workers in the United States. N Eng J Med. 2016;374:1661-9.

17. Cannavò M, Torre FL, Sestili C, et al. Work-related violence as a predictor of stress and correlated disorders in emergency department healthcare professionals. Clin Ter 2019;170:110-23.

18. Berlanda S, Pedrazza M, Fraizzoli M, de Cordova F. Addressing risks of violence against healthcare staff in emergency departments: the effects of job satisfaction and attachment style. Biomed Res Int. 2019;28:1-12.

19. Mroczek B, Mormul J, Kotwas A, Szkup M, Kurpas D. Patient aggression towards health care professionals. Prog Health Sci. 2014;4:67-74.

20. Pompeii LA, Schoenfisch AL, Lipscomb HJ, Dement JM, Smith CD, Upadhyaya M. Physical assault, physical threat, and verbal abuse perpetrated against hospital workers by patients or visitors in six US hospitals. Am J Ind Med. 2015;58:1194-204.

21. Shigeru Fujita, Shinya Ito, Seto K, Kitazawa T, Matsumoto K, Hasegawa T. Risk factors of workplace violence at hospitals in Japan. J Hosp Med. 2012;7: 79-84.

22. Partridge B, Affleck J. Verbal abuse and physical assault in the emergency department: Rates of violence, perceptions of safety, and attitudes towards security. Australas Emerg Nurs J. 2017;20:139-45.

23. Morley C, Unwin M, Peterson GM, Stankovich J, Kinsman L. Emergency Department crowding: A systematic review of causes, consequences, and solutions. PLoS One. 2018;13:1-42.

24. Gumucio S, Merica M, Luhmann N, Fauvel G, Zompi S, Ronsse A, et al. Data collection quantitative methods, the KAP survey model (knowledge, attitude, and practices). IGC communigraphie: Saint Etienne, France, 2011:4-7.

25. Benham M, Tilotson RD, Davis SM. et al. Violence in the emergency department: a national survey of emergency medicine residents and attending physicians. J Emerg Med. 2011;40:565-79.

26. Kowalenko T, Cunningham R, Sachs CJ, Gore R, Barata IA, Gates D, et al. Workplace violence in emergency medicine: current knowledge and future directions. J Emerg Med. 2012;43:523-31.

27. Chapman R, Styles I, Perry L, Combs S. Examining the characteristics of workplace violence in one non-tertiary hospital. J Clin Nurs. 2010;19:479-88.

28. Emergency Nurses Association ENA survey on prevalence of violence in U.S. ED. J Emerg Nurs. 1994;20:34A. Available from: https://www.ena.org/IENR

29. Lyneham J. Violence in New South Wales emergency departments. Australian J Adv Nurs. 2000;18:8-17.

30. The National Institute for Occupational Safety and Health. Centre for Disease Control and Prevention, U.S. Department of Health \& Human Services. Available from: https://www.cdc.gov/niosh/updates/upd-09-30-04.html

31. Al-Shiyaband AA, Ababneh RI. Consequences of workplace violence behaviours in Jordanian public hospitals. Empl Relat. 2018;40:515-28.

32. Alquisi S. The violence causes and forms of violation on the medical staff in the government and private hospitals in Jordan. Jordan J Soc Sci. 2016;9:93108.

33. Kowalczuk Kand, Krajewska-Kułak E. Patient aggression towards different professional groups of healthcare workers. Ann Agric Environ Med. 2017;24:113-6

34. Felblinger DM. Incivility and bullying in the workplace and nurses' shame responses. J Obstet Gynecol Neonatal Nurs. 2008;37:234-41.

35. Hamblin LE, Essenmacher L, Upfal MJ, Russell J, Luborsky L, Ager J, et al. Catalysts of worker-to-worker violence and incivility in hospitals. J Clin Nurs. 2015;24:2458-67.

36. Demir D, Rodwell J. Psychosocial antecedents, and consequences of workplace aggression for hospital nurses. J Nurs Scholarsh. 2012;44:376-84. 